\title{
Application of a multi-component cyclocondensation to develop a bioactive molecular scaffold
}

\author{
Sankar Chatterjee * \\ Cephalon, Inc., 145 Brandywine Parkway, West Chester, PA 19380-4245, USA \\ * Corresponding author at: 1375 Indian Creek Dr., Wynnewood, PA 19096-3321, USA. \\ Tel.: +1.610.8969125. E-mail address: sankar.chatterjee24@gmail.com (S. Chatterjee).
}

\section{COMMUNICATION INFORMATION}

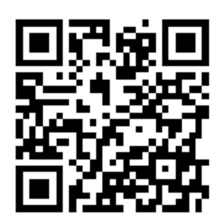

DOI: 10.5155/eurjchem.7.1.135-136.1360

Received: 09 November 2015

Received in revised form: 07 December 2015

Accepted: 13 December 2015

Published online: 31 March 2016

Printed: 31 March 2016

\section{KEYWORDS}

CNS

5-HT6

Antagonist

Benzazepine

Furanoquinoline

Cyclocondensation

\section{Introduction}

Due to its emerging role in various central nervous system (CNS) disorders, the 5-hydroxytryptamine 6 (5- $\left.\mathrm{HT}_{6}\right)$ has emerged as a promising target for the pharmacological intervention for the treatment of cognitive function in Alzheimer's disease and schizophrenia, anxiety, obesity, depression and sleep-wake activity [1-4]. In the first generation of literature reported antagonists of this receptor, a frequent feature was the presence of a sulfonamide or a sulfone moiety [5]. While profiling a chemical library we encountered compound 1, a moderately active antagonist of the $5-\mathrm{HT}_{6}$ receptor $\left(\mathrm{K}_{\mathrm{i}}\right.$ of $5,700 \mathrm{nM}$ against human $5-\mathrm{HT}_{6}$ receptor (h5-HT 6 R), Figure 1 ).

Compound 1 contained a hitherto unknown motif the 1thia-4,7-diaza-spiro[4.4]nonane-3,6-dione for the receptor's antagonism. Thus a program was initiated around this scaffold to expand the scope of the series. This research culminated in the potent antagonist, compound 2 (Figure 1, $\mathrm{K}_{\mathrm{i}}$ of $26 \mathrm{nM}$ against $\mathrm{h} 5-\mathrm{HT}_{6} \mathrm{R}$ ) [6]. While the research program aimed at developing the SAR around the central [5,5]-spiro motif (rings $\mathrm{B} / \mathrm{C}$ ) was ongoing, a parallel program also was initiated to explore whether the motif itself was needed for the potency of this class of compounds. Accordingly, the spiro bicyclic system in compound $\mathbf{1}$ was deconstructed into a linear array generating the potent antagonist, compound 3 (Ki of $10 \mathrm{nM}$ against h5- $\mathrm{HT}_{6} \mathrm{R}$, Figure 1) [7].

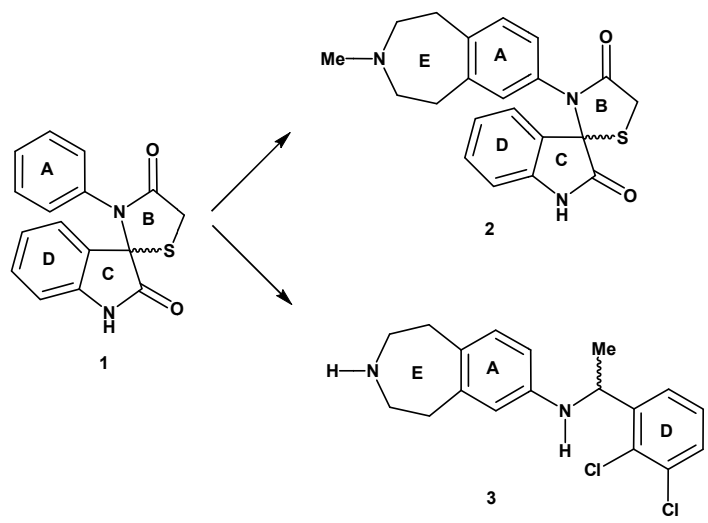

Figure 1. Structures of compounds 1, 2 and 3.

Emergence of the above-mentioned pair of potent antagonists inspired us to explore additional de novo designed series. 
Telescoping features from both compounds $\mathbf{2}$ and $\mathbf{3}$, respectively, the structural fragment $\mathbf{A}$ was envisioned followed by addition of an element of constrain between the positions as shown, as well as inclusion of a hetero atom near the constrained region (cf. compound 2). This concept gave rise to a furanoquinoline motif as exemplified in compound 4 (Figure 2, X represents varying halogen substituents) that became the scaffold to explore.

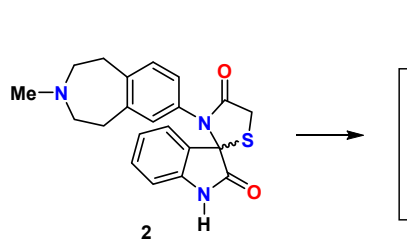

1. Constrain the depicted position 2. Add a hetero atom (O or $\mathrm{N})$
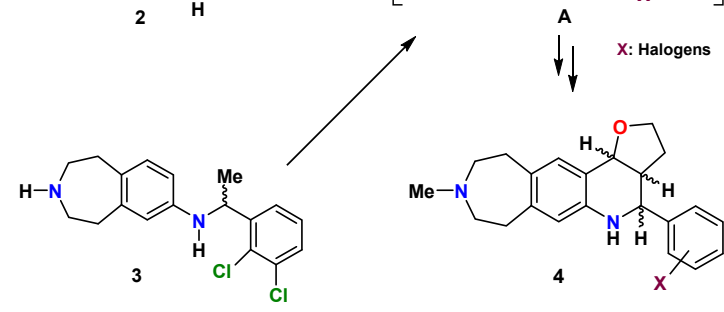

Figure 2. Evolution of compound 4.

\section{Experimental}

As depicted in Scheme 1, commercially available $N$ protected amine (compound 5), dihydrofuran 6 and various aromatic benzaldehydes (compound $7, \mathrm{X}=$ variable substituents), in presence of ceric ammonium nitrate, underwent an one pot-three components cyclocondensation reaction to generate a mixture of compounds cis-8 and trans-8 compounds, respectively [8]. To the best of our knowledge, this was the first example of a Povarov-type reaction employing a benzazepine nucleus. Each separated individual isomer then underwent following series of transformations. Deprotection of $t$-Boc group in acidic medium of compounds cis-8 and trans-8 generated compounds cis-9 and trans-9, respectively. Subsequent reductive amination of compounds cis-9 and trans-9 with paraformaldehyde generated compounds cis-4 and trans-4, respectively. Based on the partial structural feature of the active compound 3 (Figure 2), the pair cis-10 and trans-10 (generated utilizing 2,3-dichlorobenzaldehyde as one of the starting materials) became further focus of the study (vide infra).

\section{Results and discussion}

In ${ }^{1} \mathrm{H}$ NMR spectra of the cis-adduct, the coupling constant between 2-H and 3-H (quinoline numbering, Scheme 1) was 5 $\mathrm{Hz}$ due to syn-orientations of the hydrogens whereas in the trans-adduct, the corresponding value was $10 \mathrm{~Hz}$ due to antiorientation of the hydrogens. Similar trends also were reported in coupling constants between similar hydrogens in a different set of recently disclosed cis- and trans- adducts [9].

Activity of both compounds cis-10 and trans-10 were assessed against recombinant $\mathrm{h} 5-\mathrm{HT}_{6} \mathrm{R}$ following previously disclosed assay procedure [7]. Compound cis-10 displayed a $\mathrm{K}_{\mathrm{i}}$ of $90 \mathrm{nM}$, while the corresponding trans-isomer was ca. sixfold less active indicating the influence of three-dimensional structural architecture on activity. The result is the first example of a furanoquinoline-based active $5-\mathrm{HT}_{6}$ receptor antagonist.
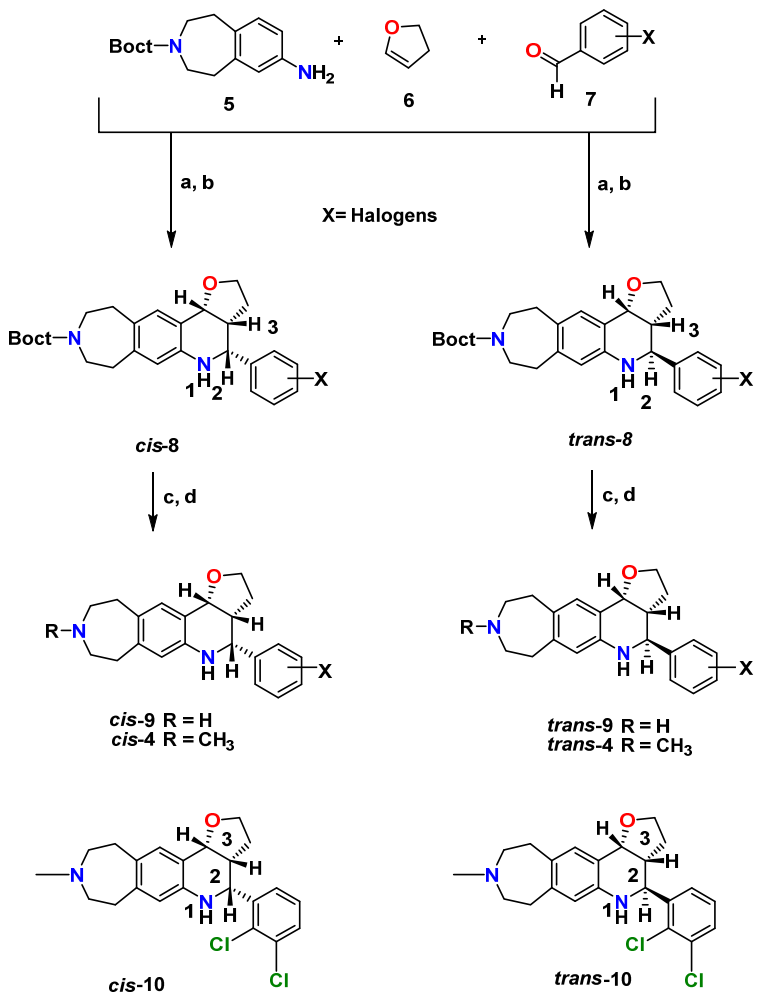

Reagents and conditions: (a) Ceric ammonium nitrate (CAN), $\mathrm{CH}_{3} \mathrm{CN}$, room temp., overnight, 75\%; (b) chromatographic separation of the isomers; (c) Individual isomer from above step (b), $4 \mathrm{~N} \mathrm{HCl}$ in dioxane, room temp., $2 \mathrm{~h}$, quantitative; (d) Individual isomer from above step c, formalin, methanol, catalytic gl. acetic acid, sodium triacetoxyborohydride, $0^{\circ} \mathrm{C}$ to room temp., 3 h, $70-75 \%$.

Scheme 1

\section{Conclusions}

Based on the structural information gleaned from previously disclosed potent compounds 2 and 3 , a series of compounds represented by compound $\mathbf{4}$ containing a furanoquinoline motif was conceptualized, synthesized and profiled for $\mathrm{h} 5-\mathrm{HT}_{6} \mathrm{R}$ antagonism. Compound cis-10 displaying a $\mathrm{K}_{\mathrm{i}}$ of $90 \mathrm{nM}$ offered a new platform for further exploration of the series.

\section{Acknowledgement}

Biology team is thanked for providing the assay data.

\section{References}

[1]. Benhamu, B.; Martiin-Fontecha, M.; Vazquez-Villa, H.; Pardo, L.; Lopez-Rodriguez, M. L. J. Med. Chem. 2014, 57, 7160-7181.

[2]. Ramirez, M. J. Alzheimer's Res. Ther. 2013, 5(15), 1-8.

[3]. Wesolowska, A. Pharmacol. Rep. 2010, 62, 564-567.

[4]. Ly, S.; Pishadari, B.; Lok, L. L.; Hajos, M.; Kocsis, B. ACS Chem. Neurosci. 2013, 4, 191-199.

[5]. Rosse, G.; Schaffhauser, H. Curr. Top. Med. Chem. 2010, 10, 207-221.

[6]. Hostetler, G.; Dunn, D.; McKenna, B. A.; Kopec, K.; Chatterjee, S. Chem Bio. Drug Des. 2014, 83, 149-153.

[7]. Hostetler, G.; Dunn, D.; McKenna, B. A.; Kopec, K.; Chatterjee, S. Chem Bio. Drug Des. 2014, 83, 666-669.

[8]. Ravindranath, N.; Ramesh, C.; Reddy, M. R.; Das, B. A. Chem. Lett. 2003, 32, 222-223.

[9]. DaSilva, B. H. S. T.; Martins, L. M.; Silva-Filho, L. C. Synlett. 2012, 23, 1973-1977. 